\title{
The Influence and Utility of Varying Field Strength for the Separation of Tryptic Peptides by Ion Mobility-Mass Spectrometry
}

\author{
Brandon T. Ruotolo, John A. McLean, Kent J. Gillig, \\ and David H. Russell \\ Laboratory for Biological Mass Spectrometry, Department of Chemistry, Texas A\&M University \\ College Station, Texas, USA
}

\begin{abstract}
The influence of field strength on the separation of tryptic peptides by drift tube-based ion mobility-mass spectrometry is reported. Operating the ion mobility drift tube at elevated field strengths (expressed in $\mathrm{V} \mathrm{cm}^{-1}$ torr $^{-1}$ ) reduces separation times and increases ion transmission efficiencies. Several accounts in the literature suggest that performing ion mobility separation at elevated field strength can change the selectivity of ion separation. To evaluate the field strength dependant selectivity of ion mobility separation, we examined a data set of 65 singly charged tryptic peptide ion signals (mass range 500-2500 m/z) at six different field strengths and four different drift gas compositions $\left(\mathrm{He}, \mathrm{N}_{2}, \mathrm{Ar}\right.$, and $\left.\mathrm{CH}_{4}\right)$. Our results clearly illustrate that changing the field strength from low field $\left(15 \mathrm{~V} \mathrm{~cm}^{-1}\right.$ torr $\left.^{-1}\right)$ to high field $\left(66 \mathrm{~V} \mathrm{~cm}^{-1}\right.$ torr $^{-1}$ ) does not significantly alter the selectivity or peak capacity of IM-MS. The implications of these results are discussed in the context of separation methodologies that rely on the field strength dependence of ion mobility for separation selectivity, e.g., high-field asymmetric ion mobility spectrometry (FAIMS). (J Am Soc Mass Spectrom 2005, 16, 158-165) (c) 2004 American Society for Mass Spectrometry
\end{abstract}

$\mathrm{H}$ ybrid mass spectrometry techniques have emerged as powerful tools for complex mixture analysis. For example, several groups have used liquid chromatography-mass spectrometry (LCMS) for identification of components of simple proteomes, and have reported enhanced sequence coverage, limit-of-detection, dynamic range, and peak capacity relative to MS-only methods of analysis $[1,2]$. Prior to the development of LC-MS techniques for proteomics, mass spectrometry of 2-D gel-separated proteins was the method of choice for large-scale protein identification, because the method provides both excellent peak capacity and modestly improved dynamic range [3, 4]. However, both LC and 2-D gel separations inefficiently utilize MS detection, because separations can take 5 to 10 orders of magnitude longer than necessary for mass spectrometry detection (i.e., $<100 \mu$ s for time-of-flight (TOF) MS) [5].

Ion mobility (IM) separation (based on ion collision cross-section) coupled with mass spectrometry possesses many of the same advantages of LC-MS approaches, i.e., enhanced dynamic range and increased peak capacity when compared with MS-only analysis $[6,7]$. Further, IM separations require only milliseconds

Published online December 9, 2004

Address reprint requests to Dr. D. H. Russell, Laboratory for Biological Mass Spectrometry, Department of Chemistry, Texas A and M University, P.O. Box 30012, College Station, TX 77843, USA. E-mail: russell@mail.chem.tamu.edu (typically $500 \mu$ s to $2 \mathrm{~ms}$ for tryptic peptides), which is better suited to MS timescales [8]. For example, both Russell (using matrix assisted laser desorption ionization - MALDI) and Clemmer (using electrospray ionization - ESI) have utilized IM-MS for the analysis of complex protein mixtures $[9,10]$. In the case of MALDIIM-MS protein mixture analysis, the hybrid separation technique provided enhanced percent amino acid sequence coverage through the increased dynamic range relative to MS-only analysis [9]. Clemmer and coworkers used LC-ESI-IM-MS to analyze biologically derived complex mixtures, and demonstrated that the combination of LC and IM provides complementary separation steps for the analysis of peptides [10].

Although IM-MS separations are relatively rapid in comparison with LC-MS, the peak capacity for IM-MS is relatively low (ca. $5 \times 10^{3}$ for IM-MS and $1 \times 10^{7}$ for LC-MS) [11, 12]. For a single homologous series of ions (all having the same ionic charge), there is a high degree of correlation between the drift time dimension (ion mobility) and the mass of the ion $(\mathrm{m} / \mathrm{z})$. This apparent mass-mobility correlation holds for a large percentage $(>97 \%)$ of tryptic peptides, but a small number of ions $(\sim 3 \%)$ exhibit conformational differences in the gasphase (i.e., helices), which increases the peak capacity for peptide ion signals [13]. Characteristic differences in mass-mobility correlation are also observed for posttranslationally modified peptides (i.e., phosphorylated) [14] or metal-cationized (i.e., alkali metal adducted) 
peptide ions $[15,16]$. In general, IM-MS separations can enhance the peak capacity by factors of 5 to 10 over MS alone [11, 12].

Two primary methods are typically utilized to alter the selectivity (and hence the peak capacity) of IM separations: (1) altering the neutral drift gas composition [17] and (2) changing the field strength of the separation [18]. Changing drift gas composition can promote selectivity if a significant interaction potential between the ion and neutral drift gas is induced. In some cases, by altering the lifetime of the ion-neutral collision complex, IM separation selectivity can be tuned. For example, this approach is effective for small peptides and organics $(<500 \mathrm{~m} / \mathrm{z})[19,20]$, and recent results have indicated that only limited separation selectivity is achieved for larger, singly-charged tryptic peptides (e.g., 500-2500 m/z) [12].

Altering the field strength of IM separations can also be used to change the separation selectivity. Separations performed by IM are typically classified as "low"- or "high"-field separations, depending upon whether the ion gains translational energy between collisions (highfield) or achieve a steady-state drift velocity (low-field) [21]. By performing IM separations at field strengths that exceed the low-field limit, the apparent mobility for some ions (primarily atomics and small organic molecules) will change as a function of field strength. The mechanism(s) by which mobility changes as a function of field strength is not well understood, although for atomic and diatomic species (i.e., $\mathrm{O}_{2}$ ) charge exchange reaction chemistry is thought to contribute significantly to the observed changes [21]. Several groups utilizing high-field asymmetric waveform ion mobility spectrometry (FAIMS, an atmospheric pressure IM method that uses a combination of high- and low-field separation) have reported enhanced selectivity by operating at high field strength ( $\sim 35$ to $50 \mathrm{~V} \mathrm{~cm}^{-1}$ torr $^{-1}$ or 100 to $140 \mathrm{Td}$ ) for a wide range of compounds, including tryptic peptides $[22,23]$; however, recent studies on the mechanism of FAIMS separation suggest that clustering/de-clustering reactions between solvent molecules or drift gas impurities may also influence the separation process [24, 25].

The primary motivation for high field IM is faster separation times, which increases the overall throughput of the experiment. This is especially important for MALDI-IM-MS instruments using high-repetition rate laser systems (e.g., 1-10 KHz), because fast separation times are required to retain a near $100 \%$ duty cycle [26]. In addition, IM separation at higher field strengths ( $>50 \mathrm{~V} \mathrm{~cm}^{-1}$ torr $^{-1}$ ) facilitates separations of both high resolution and high sensitivity. Resolution generally increases with increasing separation voltage [27] but diffusion, (both longitudinal and radial) does not dramatically increase at IM-relevant field strengths (i.e., below the breakdown voltage for typical IM cell designs/pressures) for ions within the mass range of typical tryptic peptide ions $(500-2500 \mathrm{~m} / \mathrm{z})$, allowing both high resolution and enhanced ion transmission efficiency. Disadvantages of high-field strength IM separations include the potentially unpredictable nature in which ion mobility changes as a function of field strength; an effect that, for peptides and proteins, is presumably influenced by changes in the gas-phase conformation through a field-dependant ion heating mechanism [22, 23].

This report evaluates high-field strength IM separations for the analysis of tryptic peptides. To effectively assess the ability of field strength to alter the IM separation selectivity for tryptic peptide ions, we examined a data set of 65 peptides at six field strengths (15-66 $\mathrm{V} \mathrm{cm}^{-1}$ torr $^{-1}$ ) and four gas compositions. These results indicate that changing the field strength over the range studied here does not significantly alter the selectivity or peak capacity of IM-MS for tryptic peptides, presumably due to the conformational integrity of tryptic peptide ions at these field strengths. The implications of these results are discussed in the context of separation methodologies that rely on the field strength dependence of tryptic peptide ion mobility (i.e., FAIMS), for separation selectivity.

\section{Experiment}

\section{Sample Preparation}

Protein digest samples of horse heart myoglobin, rabbit muscle aldolase, bovine hemoglobin, chicken egg white lysozyme, bovine serum albumin, and horse heart cytochrome $c$ (Sigma, St. Louis, MO) were prepared as described previously [11]. Briefly, micromolar concentrations of protein were heated to $90 \mathrm{~s}^{\circ} \mathrm{C}$ for $30 \mathrm{~min}$, allowed to cool at ca. $-15 \mathrm{~s}^{\circ} \mathrm{C}$ for $5 \mathrm{~min}$ (to quench the thermal denaturation process) [28], then mixed in a 40:1 substrate-to-enzyme ratio with sequencing grademodified trypsin (Promega, Madison, WI) and allowed to react for $4 \mathrm{~h}$. Samples were mixed in a 100:1 matrixto-analyte ratio with $\alpha$-cyano-4-hydroxycinnamic acid MALDI-IM-MS analysis.

\section{Ion Mobility-Mass Spectrometry}

The MALDI-IM-TOFMS instrument used in these studies was built in-house and described in detail elsewhere [29]. Briefly, the instrument consists of a MALDI ion source equipped with a high repetition rate-frequency tripled Nd:YAG laser (355 nm, JDS Uniphase, San Jose, CA) typically operated at a repetition rate of $200-400 \mathrm{~Hz}$. The drift cell is a $30.5 \mathrm{~cm}$ periodic focusing design [30], operated at 0.75 to 1 torr of high-purity $\mathrm{He}, \mathrm{N}_{2}, \mathrm{CH}_{4}$, or $\mathrm{Ar}$ measured using a capacitance manometer (Inficon, Balzers, Liechtenstein) at $26-27 \mathrm{~s}^{\circ} \mathrm{C}$. Using these experimental conditions we routinely achieve mobility resolution of 30-60 for peptide ions. Ions exiting the drift cell are focused by a 5-element einzel lens into the orthogonal extraction source of a 2-stage reflectron TOFMS $(\sim 1 \mathrm{~m}$ path length mass resolution $\sim 400-1000)$. Data is collected on a computer controlled time-to-digital converter (Ion- 
werks, Houston TX.), using 2-D acquisition software specifically designed for the IM-MS experiment (Ionwerks). Contour plots shown here are produced using Transform and related programs included in the IDL software environment (Research Systems, Boulder, CO).

Estimates of the low field limit, in $\mathrm{V} \mathrm{cm}^{-1}$ torr $^{-1}$ $\left(E_{0} / p\right)$, are made utilizing eq 1 . As previously described by Mason [31]:

$$
\frac{E_{0}}{p}=0.354 \frac{E_{0}}{N}<\left(\frac{m}{m+M}\right)^{1 / 2} \frac{d^{2}}{q}
$$

where $\mathrm{m}$ is the ion mass, $\mathrm{M}$ is the mass of the neutral target gas, $\mathrm{d}$ is the diameter of the ion, and $\mathrm{q}$ is the number of charges on the ion (for these calculations $q=1$ ). The output of the published equation is in $\mathrm{Td}\left(\mathrm{E}_{0} / \mathrm{N}\right)$, and the conversion factor given for $\mathrm{V} \mathrm{cm}^{-1}$ torr $^{-1}$ (0.354) assumes that the measurements are made at room temperature. Note that the error of the low field limit calculation increases at higher values of $E_{0} / p$. For the trends shown in Figure 5 and other estimates made in the text, values for the diameter $(\mathrm{d})$ of singly charged gas-phase peptide ions were taken from a large available database of peptide collision cross-sections published by Clemmer and coworkers [32] as well as those measured in our laboratory (assuming that $\Omega \approx \pi \mathrm{d}^{2}$ ).

\section{Peak Capacity Calculations}

Peak capacity was calculated by measuring the spread of IM-MS data by fitting the positions of peptide ion signals (in drift time and $\mathrm{m} / \mathrm{z}$ ), to a linear relationship and determining the residuals [11]. Although a polynomial type description of the drift time- $m / z$ relationship, which provides a better approximation of the drift time- $m / z$ relationship over a large mass range, does not provide a significant difference in the peak capacity estimate relative to the linear relationship used here [12]. The drift time- $m / z$ area occupied by peptide ion signals was calculated in terms of number of peaks that can be resolved (at half-height) in the given separation area, assuming an average mobility resolution of 50 and MS resolution of 400. Although IM resolution was clearly not a constant in the results reported here (as the

\section{(a)}

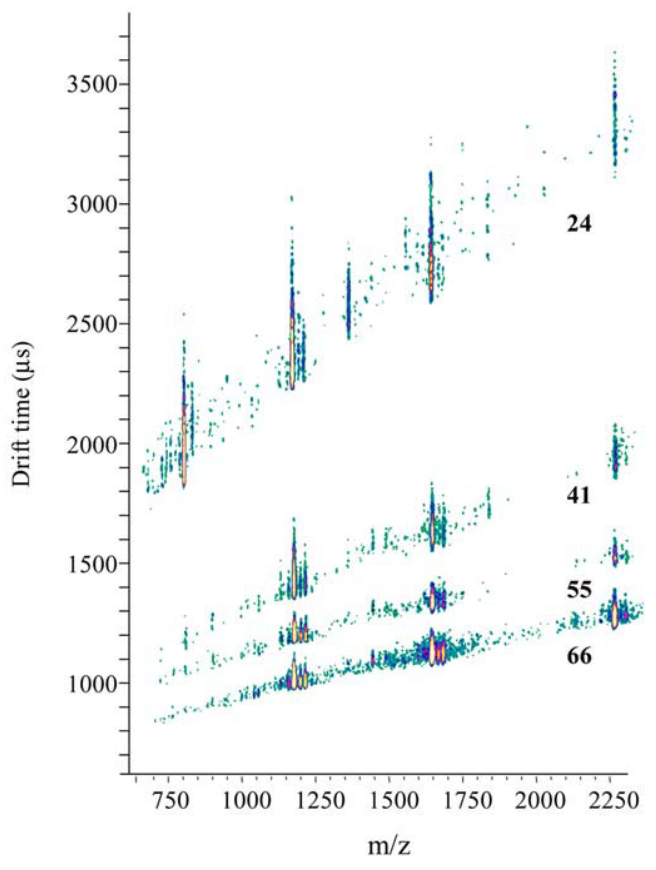

(b)

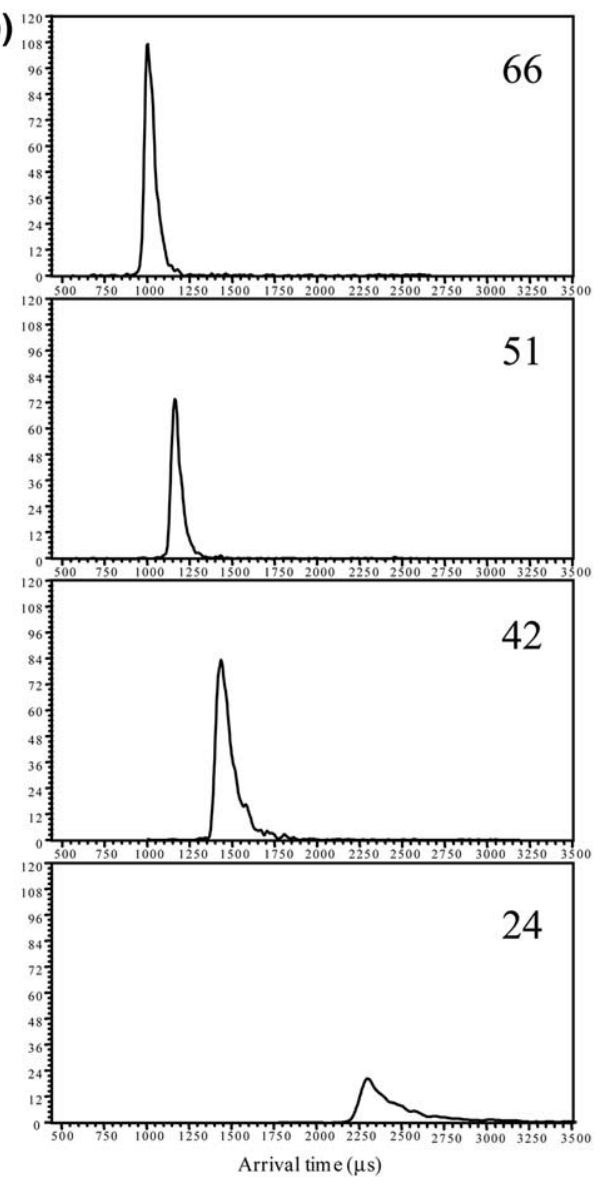

Figure 1. (a) An overlay of 4 plots of drift time versus $m / z$ taken at four field strengths: 66 (bottom), 55, 41 , and 24 (top) $\mathrm{V} \mathrm{cm}^{-1}$ torr $^{-1}$ for a protein digest of cytochrome $c$ (horse heart) utilizing $\mathrm{N}_{2}$ as the drift gas. (b) Arrival time distributions for the tryptic peptide at $m / z 1169$ illustrating the resolution decrease as a function of applied voltage from ca. 35 (top) to ca. 10 (bottom). The field strengths utilized to acquire each spectrum are noted in the upper right-hand corner of each panel in $\mathrm{V} \mathrm{cm}^{-1} \mathrm{torr}^{-1}$. 


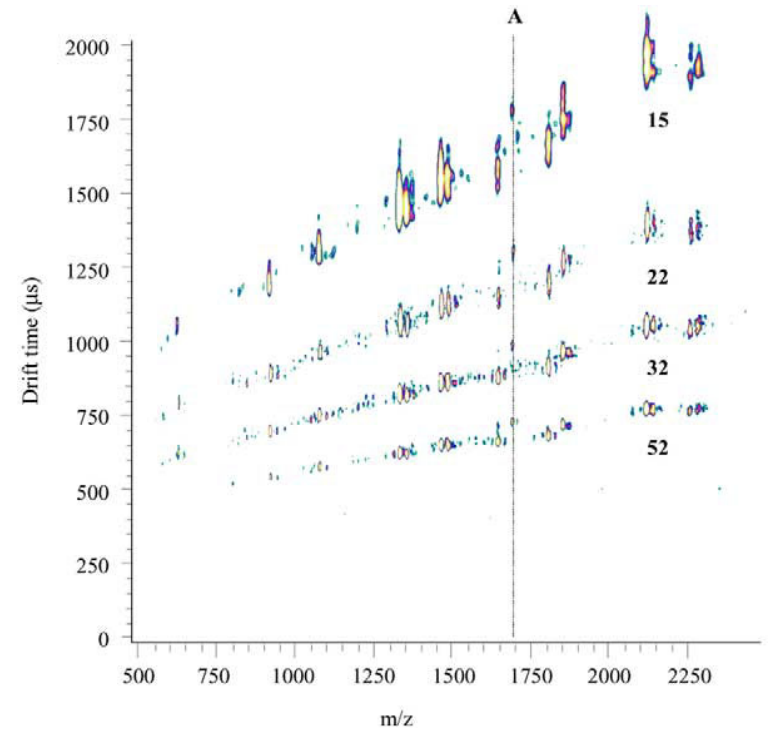

Figure 2. An overlay of 4 plots of drift time versus $\mathrm{m} / \mathrm{z}$ taken at four field strengths: 52 (bottom), 32, 22, and 15 (top) $\mathrm{V} \mathrm{cm}^{-1}$ torr $^{-1}$ for a protein digest of aldolase (rabbit muscle) utilizing $\mathrm{He}$ as the drift gas. An outlier peptide exhibiting extended secondary structure, YSHEEIAMATVTALR (m/z 1693), is labeled with a vertical line $(\mathbf{A})$.

voltage across the drift cell was utilized to vary the separation field strength), a constant resolution of 50 was used for all field strengths to investigate the influence of field strength on the selectivity/peak capacity of IM-MS separation. It is important to note that varying the gas pressure could also be utilized to access the same field strengths, and retain IM resolution (although with less precision and reproducibility).

\section{Results and Discussion}

Figure 1a shows an overlay of four plots of drift time versus $\mathrm{m} / \mathrm{z}$ for a tryptic digest of horse cytochrome c utilizing $\mathrm{N}_{2}$ drift gas. The data were acquired at field strengths of $24,41,55$, and $66 \mathrm{~V} \mathrm{~cm}^{-1}$ torr $^{-1}$. The slopes for each drift time- $m / z$ plot are field dependant (ranging from 0.3 at $66 \mathrm{~V} \mathrm{~cm}^{-1}$ torr ${ }^{-1}$ to 0.9 at $24 \mathrm{~V} \mathrm{~cm}^{-1}$ torr $^{-1}$ ) because the total drift time that the ions experience decreases with increasing drift voltage, but the $\mathrm{m} / \mathrm{z}$ of the ions are independent of the conditions used for mobility separation. Note that the ions observed in the plot acquired at $24 \mathrm{~V}$ $\mathrm{cm}^{-1}$ torr $^{-1}$ are within the low-field limit for the mass range of the majority of the peptides studied here (most peptide ions above $\mathrm{m} / \mathrm{z} \sim 850$ have collision cross sections large enough to be within the low-field limit at a field strength of $24 \mathrm{~V} \mathrm{~cm}^{-1}$ torr $^{-1}$ ). The collision energies obtained at 41,55 , and $66 \mathrm{~V} \mathrm{~cm}^{-1}$ torr $^{-1}$, however, exceed the low field limit for successively larger fractions of the peptide ions observed. For example, at $41 \mathrm{~V} \mathrm{~cm}^{-1}$ torr $^{-1}$ an ion of $\mathrm{m} / \mathrm{z} 2500$ is still under low field conditions because the collision cross section for the ion is large, whereas high-field conditions for the same ion are achieved at $66 \mathrm{~V} \mathrm{~cm}^{-1}$ torr $^{-1}$ [31]. Note that estimates of the low field limit made here were performed utilizing an equation previously described by Mason [31] and ionneutral collision cross-sections taken from the data presented here, as well as those published previously [32].

Figure 1a illustrates an important feature of the dataset presented here: no significant change in relative position between two analyte ions in drift time- $m / z$ space (separation selectivity) is observed as a function of field strength. Noticeable differences are observed, however, in both the IM peak width (see Figure 1b) and the relative intensity of the signals observed. For example, the data taken at a field strength of $24 \mathrm{~V} \mathrm{~cm}^{-1}$ torr $^{-1}$ shows two signals $(\mathrm{m} / \mathrm{z} 806.9$ and 1359.3) that appear in higher abundance than at the other three field strengths. Note that the sampling rate of the TOF was kept constant in these experiments (interleaved TOF sampling every $5 \mu \mathrm{s}$ ) [33]. A possible explanation for the variation in signal at different field strengths is that the sampling efficiency for the analyte ions was increased because the peak widths in the drift time dimension at low field strength are broadened relative to the same ion signals observed at high field strength, thus allowing the TOF to acquire a greater number of mass spectra for a given analyte under low field IM conditions relative to high field at a fixed sampling rate. Alternatively, we cannot rule out an ion stabilization mechanism that would enhance the relative ion signal for metastable species created by MALDI ionization at lower field strengths [9]. Further, note that increased tailing is observed at decreased field strengths. While the peak width broadening is in agreement with the known relationship between applied voltage and IM resolution [27], there are many potential sources of the observed tailing. These sources include: incomplete dissociation of matrix-analyte clusters from the MALDI event, the presence of multiple gas-phase peptide conformations, and ion-neutral interactions in the drift tube. Note that the observation of tailing does not change the analytical results of the separation, i.e.,

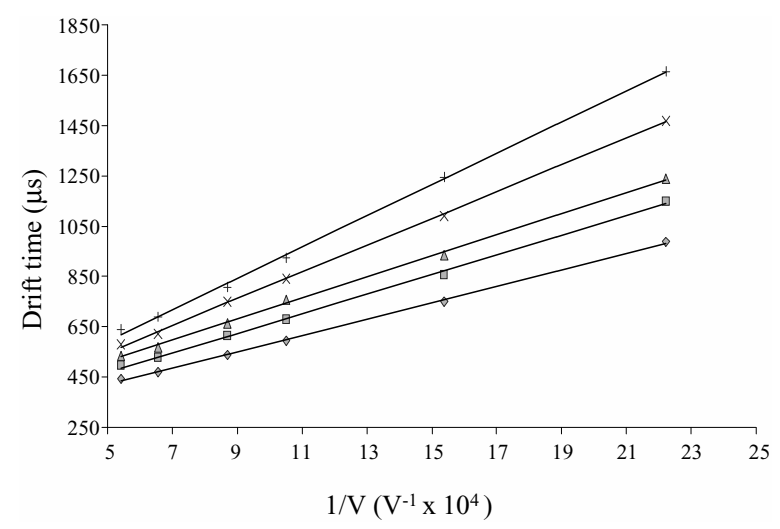

Figure 3. A plot of drift time versus I/V for five peptide sequences from a tryptic digest of chicken egg white lysozyme: KVFGR (filled diamonds), HGLDNYR (filled squares), GTDVQAWIR (filled triangles), CKGTDVQAWIR (x), NTDGSTDYGILQINSR (+). 
tailing does not affect the selectivity or peak capacity of the separation.

Figure 2 contains plots of drift time versus $\mathrm{m} / \mathrm{z}$ for a protein digest of rabbit muscle aldolase, which further illustrates the independence of relative drift time differences for tryptic peptides from changes in field strength. The peptide ion signal labeled A in Figure 2 corresponds to the protonated ion of YSHEEIAMATVTALR $(\mathrm{m} / \mathrm{z}$ 1693), a peptide ion that exhibits extended (most probably helical) structure in the gas phase [13]. Note that the position of this ion signal relative to the ion signal at $\mathrm{m} / \mathrm{z} 1648$ remains relatively constant (ca. $12 \%$ difference in relative drift time). In general, small differences are observed in relative drift time difference at different field strengths $(<1 \%)$, but these differences exhibit no discernable trend with field strength and do not appear to indicate a significant change in separation selectivity or peak capacity.

Figure 3 contains a plot of drift time vs. 1/V (separation ranging from 15 to $62 \mathrm{~V} \mathrm{~cm}^{-1}$ torr $^{-1}$ ) for five tryptic peptides from chicken egg white lysozyme which further indicates the lack of a discernable difference between high-field and low-field mobility values for tryptic peptides. The slope of each line shown in Figure 3 is related to the mobility of the ion measured. If the mobility of the peptide ions changed significantly as a function of field strength, we would expect the correlation coefficient to a linear fit of the data to be low. The correlation coefficients for all linear fits shown in Figure 2 are $>0.998$, the average correlation coefficient obtained from the analysis of all 149 trials (65 peptide sequences in $\mathrm{He}$, and 30 peptide signals in $\mathrm{N}_{2}, \mathrm{CH}_{4}$, and $\mathrm{Ar}$ ) for ion signals investigated here was 0.999 .

The overall spread of tryptic peptide signals in drift time- $m / z$ space as a function of field strength is illustrated by Figure 4, a series of plots depicting how the numbers of peptides vary as a function of deviation from linear fit. As discussed in previous work, such plots can be viewed as a probability density diagram for the appearance area (i.e., separation space) of tryptic peptides by IM-MS [12]. The data presented in Figure 4 indicates that when the field strength is high, the overall deviation of tryptic peptides from a linear fit is low (signals are highly correlated to a linear relationship between drift time and $m / z$ ), and the numbers of peptides observed having a small deviation from a linear fit $( \pm 1 \%)$ is high. On the other hand, a greater degree of spread is observed as the field strength is decreased, and the population of peptides that are highly correlated to the linear relationship between drift time and $\mathrm{m} / \mathrm{z}$ is decreased going from $62 \mathrm{~V} \mathrm{~cm}^{-1}$ torr $^{-1}$ to $15 \mathrm{~V}$ $\mathrm{cm}^{-1}$ torr $^{-1}$ indicating an increased appearance area for peptide ion signals at decreased field strength. Although potentially indicative of an increase in peak capacity, some increase in absolute appearance area is expected assuming peak capacity for the separation remains constant, because IM peak widths will broaden at longer drift times (at fixed mobility resolution). Therefore, to increase IM-MS peak capacity, the broad-

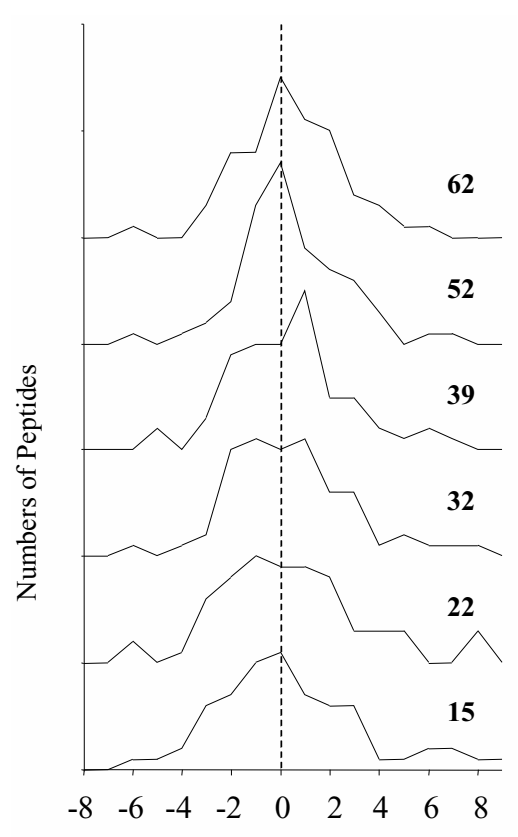

Percent Deviation from Linear Fit (\%)

Figure 4. Plot of numbers of peptides vs. deviation from a linear fit (probability distribution plots) for six field strengths in $\mathrm{He}$ decreasing from 62 (top) to 15 (bottom) $\mathrm{V} \mathrm{cm}^{-1}$ torr $^{-1}$.

ening of the appearance area for peptide ion signals (i.e., the separation space) must increase to a greater degree than the amount of broadening predicted by the increased peak widths at longer drift times. The amount of increase in separation space observed in Figure 4 (approximately a factor of 2 greater at 62 versus $15 \mathrm{~V}$ $\mathrm{cm}^{-1}$ torr $^{-1}$ ) correlates well with the increase in separation space predicted by the increase of peak width at longer drift times, indicating that no measurable change in peak capacity for singly charged peptide ions is accomplished by operating the IM separation at field strengths that exceed the low field limit.

The data presented here may be particularly relevant to questions regarding the mechanism of FAIMS separation [23]. Previously, several groups have suggested that the separation of peptide ions by FAIMS is primarily influenced by differences between the physics of ion transport under high- and low-field conditions. The proposed mechanism(s) predicts an enhanced selectivity for FAIMS separation over conventional IMS separation under conditions where two ions having the same (or indistinguishable) low-field mobilities exhibit different mobilities under high-field conditions, owing to differences in either ion diffusion or physical shapes of the analyte ions (i.e., conformation). Presumably, the increased peak capacity of a FAIMS peptide separation over a conventional IMS approach is achieved by a similar mechanism. The data presented here suggests that $\mathrm{K}_{\mathrm{h}} / \mathrm{K} \approx 1$ for the majority of tryptic peptides investigated, and those ions that do exhibit a change in high- versus low-field mobilities all exhibit a decreased mobility at high field (i.e., C-type ion behavior in 


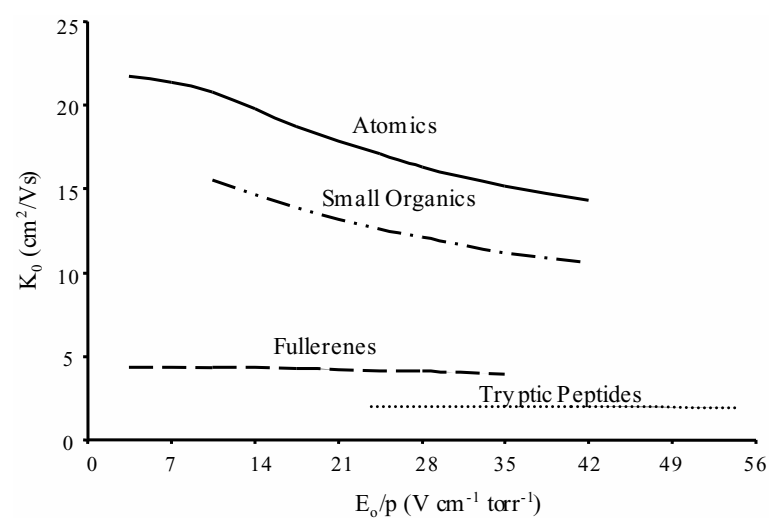

Figure 5. Plot of $\mathrm{K}_{\mathrm{o}}$ versus $\mathrm{E}_{\mathrm{o}} / \mathrm{p}$ for several ions representative of the trends observed for ions over a wide range of $\mathrm{m} / \mathrm{z}$ values under experimental conditions that limit ion-neutral interactions/reactions. Atomic data for $\mathrm{Ar}^{+}$from reference and small organic data for $\mathrm{CH}_{3} \mathrm{CHOH}^{+}$from reference [36], fullerene data for $\mathrm{C}_{60}{ }^{+}$from reference [37], and tryptic peptide data for NTDGSTDYGILQINSR $[\mathrm{M}+\mathrm{H}]^{+}$ion from this work.

FAIMS experiments). Our observations are consistent with the current FAIMS data on tryptic peptides, as such analytes exhibit C-type ion behavior and small $(<1 \%)$ differences between high and low field mobilities.

There are several aspects of our data that are seemingly inconsistent with a FAIMS mechanism based strictly on the physical differences between high-field and low field diffusion or conformational changes of the analyte. First and foremost, no observable alterations in separation selectivity or peak capacity are detected for tryptic peptide ions as a function of field strength for the data presented here. Specifically, while ion mobility is independent of field strength at low $\mathrm{E}_{0} / \mathrm{p}$, the small differences observed between high and low field mobility for tryptic peptides are consistent with the following relationship:

$$
\mathrm{K} \propto\left(\mathrm{E}_{0} / \mathrm{p}\right)^{-1 / 2}
$$

first expressed by Wannier, and since covered in several texts [34-36]. As dictated by eq 2, the mobilities of tryptic peptide ions decrease slightly at high field strengths. As shown in Figure 5, a plot of $\mathrm{K}_{0} \mathrm{vs} . \mathrm{E}_{0} / \mathrm{p}$, this observation is also consistent with other IMS measurements on a wide range of analytes including atomic, small organic, and fullerene ions [37, 38]. The representative data for the additional classes of ions

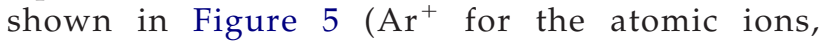
$\mathrm{CH}_{3} \mathrm{CHOH}^{+}$for small organic ions, $\mathrm{C}_{60}{ }^{+}$for fullerene ions, and NTDGSTDYGILQINSR for the $[\mathrm{M}+\mathrm{H}]^{+}$ tryptic peptide ions) were all acquired under conditions that minimize the influence of gas-phase chemistry on the mobility separation (i.e., low pressure, high gas purity, low relative humidity) and thus emphasizing the influence of ion transport at high field strengths on the separation, with the effect of high field diffusion more pronounced for the higher mobility species. Over- all, the tryptic peptide data presented here is completely consistent with eq 2 and the literature data presented in Figure 5, indicating that the effects of drift cell reaction chemistry on the tryptic peptide separation are minimized.

It is important to note that the high field separations performed here are within the field strength range of most FAIMS experiments (for singly charged ions), and we find no evidence to suggest that the conformation or mobility behavior of gas-phase peptide ions is influenced by field strengths in the range of $\sim 15-70 \mathrm{~V} \mathrm{~cm}^{-1}$ torr $^{-1}(\sim 40-200 \mathrm{Td})$. Figure 6 shows two field strength ranges (for FAIMS and this work) relative to the theoretical low-field limit (for singly charged peptide ions) on a plot of field strength vs. mass [21, 31, 32]. While the typical high-field strength portion of the FAIMS waveform produces an estimated field strength that only exceeds the low field limit for the smallest singly charged tryptic peptide ions $\left(26 \mathrm{~V} \mathrm{~cm}^{-1}\right.$ torr $\left.^{-1}\right)[23,39]$, the data presented here extends to field strengths that encompass all singly charged peptide ions. For multiply charged peptide ions, the effective field strength (field strength multiplied by ionic charge) of FAIMS separation can approach $70-80 \mathrm{~V} \mathrm{~cm}^{-1}$ torr $^{-1}[18,23]$; however, it should be noted that the upper bound of the field strengths utilized in these studies is comparable to the effective field strengths utilized for FAIMS separation of multiply charged (doubly and triply) tryptic peptide ions. The estimates shown in Figure 6 indicate that the field strengths used in these studies should be sufficient to detect differences between high-field and low-field mobilities for tryptic peptides irrespective of the charge states of the ions. Recently, several groups have suggested that the selectivity achieved in FAIMS separation is based on a clustering/de-clustering mechanism. For example, Eiceman and coworkers have reported that the level of moisture present in the drift gas utilized for separation strongly influences the fielddependent separation of orgaonophosphorus compounds [24]. On the basis of our measurements, it seems unlikely that FAIMS separation of peptide ions is based entirely on either differences in high-field diffusion or peptide ion conformation relative to low-field conditions, but our results may be interpreted as evidence to support alternative mechanism(s), specifically clustering/de-clustering, where selectivity or peak capacity enhancements are the result of ion-neutral interactions.*

\section{Conclusions}

Although the selectivity of IM separation of tryptic peptides $(m / z=500-2500)$ is limited, IM-MS has several advantages for complex mixture analysis over other separation techniques that have a high degree of or-

\footnotetext{
* In a recent paper, Shvartsburg and Smith recently described enhanced resolution for FAIMS separation of peptide ions by using SF6/He gas mixtures, and their observations provide additional support for Eiceman's proposed dependence of FAIMS separation on ion-neutral interactions.
} 


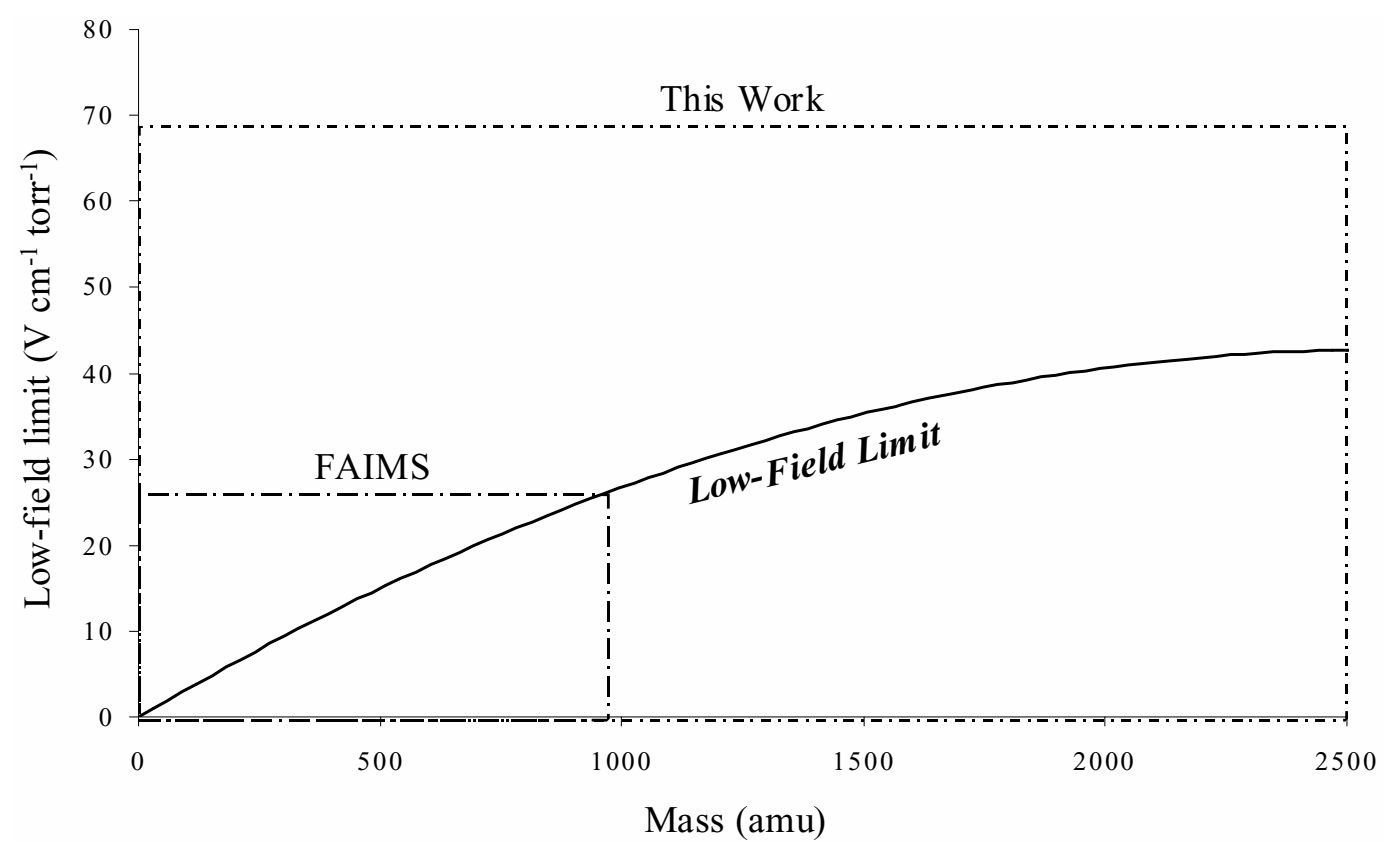

Figure 6. Plot of field strength $\left(\mathrm{V} \mathrm{cm}^{-1} \mathrm{torr}^{-1}\right)$ versus mass $(\mathrm{amu})$, showing the low field limit calculated for singly charged tryptic peptide ions (using eq 1) relative to the field strength utilized in the high-field portion of the FAIMS waveform (from references [23] and [39]) and the work presented here (both shown by labeled dashed lines).

thogonality to mass spectrometry. Primary among these advantages are the speed of separation ( $\mu \mathrm{s}-\mathrm{ms})$ and the ability to separate ions on the basis of structure, compound class (packing efficiency), and charge state, thus increasing the signal-to-noise of the individual components by reducing chemical noise. These advantages are not lost by operating the instrument at higher field strengths, and in some cases the intrinsic advantages of IM over other separation techniques are enhanced relative to low-field separations, i.e., enhanced throughput. In addition, IM separation typically provides a gain of a factor of 5-10 in terms of peak capacity over mass spectrometry alone, enabling the analysis of complex mixtures when coupled to high-resolution mass spectrometry. In addition, for cases where multiple trend lines are present (i.e., mixtures of peptide, DNA, lipids, etc.), peak capacity is additive, and can result in a gain of a factor of ca. 30 (in the case of three fully resolved trend lines) in peak capacity over MS alone [11].

The data presented here indicates that the peak capacity and selectivity of peptide separation by IM does not change over the range of field strengths examined ( 15-66 $\mathrm{V} \mathrm{cm}^{-1}$ torr $\left.^{-1}\right)$. Our experimental results are also consistent with Wannier's description of the differences between high and low field diffusion, as expressed by eq 2, and other experimental data where the influence of ion-neutral interactions and reactions on ion mobility are minimized (Figure 5). Furthermore, such a theoretical interpretation of the data reduces the possibility of selectivity enhancement at high field as ions that have the same mobility under low field conditions will exhibit precisely the same change in ion mobility at high fields. The data shown in Figure 5 also indicates that as field strength is increased the separation between analyte ions in mobility universally decreases, thus predicting a decreased peak capacity for high-field ion mobility separation. The preceding interpretation of the available experimental data contradicts suggestions that the FAIMS separation of protein digest mixtures is based exclusively on differences in high field and low field diffusion or conformational transitions of peptide ions induced by high field conditions [23], and suggests that an alternative mechanism(s), most probably owing to some type of reaction chemistry rather than changes in the hard-sphere collision cross-section, is operative for the separation of peptides ( $m / z$ 500-2500) by FAIMS where enhanced selectivity or peak capacity is observed [24]. While a definitive explanation of the FAIMS mechanism is currently unavailable, further studies aimed at identifying the role of gas-phase ion chemistry in FAIMS separation are ongoing.

\section{Acknowledgments}

Funding for this research is provided by the National Science Foundation (CHE-9629966), the U.S. Department of Energy, Division of Chemical Sciences, Basic Energy Science (DE-FG0395ER14505), and the Texas Advance Research Program/Technology Development/Transfer (TARP/TDT, 010366-0064-2001).

\section{References}

1. McDonald, W. H.; Yates, J. R., III. Shotgun proteomics and biomarker discovery. Dis. Mark. 2002, 18, 99-105. 
2. Shen, Y.; Tolic, N.; Zhao, R.; Pasa-Tolic, L.; Li, L.; Berger, S. J.; Harkewicz, R.; Anderson, G. A.; Belov, M. E.; Smith, R. D. High-throughput proteomics using high- efficiency multiplecapillary liquid chromatography with on-line high-performance ESI FTICR mass spectrometry. Anal. Chem. 2001, 73, 3011-3021.

3. Figeys, D. Proteomics in 2002: A year of technical development and wide-ranging applications. Anal. Chem. 2003, 75, 2891-2905.

4. Smith, R. D.; Shen, Y.; Tang, K. Ultrasensitive and quantitative analyses from combined separations-mass spectrometry for the characterization of proteomes. Accounts Chem. Res. 2004, $37,269-278$.

5. Holland, J. F.; Enke, C. G.; Allison, J.; Stults, J. T.; Pinkston, J. D.; Newcome, B.; Watson, J. T. Mass spectrometry on the chromatographic time scale: Realistic expectations. Anal. Chem. 1983, 55, 997A-1012A.

6. Gillig, K. J.; Ruotolo, B; Stone, E. G.; Russell, D. H.; Fuhrer, K.; Gonin, M.; Schultz, A. J. Coupling high-pressure MALDI with ion mobility/orthogonal time-of-flight mass spectrometry. Anal. Chem. 2000, 72, 3965-3971.

7. Ruotolo, B. T.; Gillig, K. J.; Russell, D. H. Post-ionization sample "clean-up" utilizing ion mobility-mass spectrometry, unpublished.

8. Hoaglund-Hyzer, C. S.; Counterman, A. E.; Clemmer, D. E. Anhydrous protein ions. Chem. Rev. 1999, 99, 3037-3079.

9. Ruotolo, B. T.; Gillig, K. J.; Stone, E. G.; Russell, D. H.; Fuhrer, K.; Gonin, M.; Schultz, J. A. Analysis of protein mixtures by matrix-assisted laser desorption ionization-ion mobility-orthogonal time-of-flight mass spectrometry. Int. J. Mass Spectrom. 2002, 219, 253-267.

10. Hilderbrand, A. E.; Myung, S.; Srebalus Barnes, C. A.; Clemmer, D. E. Development of LC-IMS-CID-TOFMS techniques: Analysis of a 256 component tetrapeptide combinatorial library. J. Am. Soc. Mass Spectrom. 2003, 14, 1424-1436.

11. Ruotolo, B. T.; Gillig, K. J.; Stone, E. G.; Russell, D. H. Peak capacity of ion mobility mass spectrometry: Separation of peptides in helium buffer gas. J. Chrom. B 2002, 782, 385-392.

12. Ruotolo, B. T.; Mclean, J. A.; Gillig, K. J.; Russell, D. H. Peak capacity of ion mobility mass spectrometry: The utility of varying drift gas polarizability for the separation of tryptic peptides. J. Mass Spectrom. 2004 39,361-367.

13. Ruotolo, B. T.; Verbeck, G. F.; Thomson, L. M.; Gillig, K. J.; Russell, D. H. Observation of conserved solution-phase secondary structure in gas-phase tryptic peptides. J. Am. Chem. Soc. 2002, 124, 4214-4215.

14. Ruotolo, B. T.; Verbeck, G. F., IV; Thomson, L. M.; Woods, A. S.; Gillig, K. J.; Russell, D. H. Distinguishing between phosphorylated and nonphosphorylated peptides with ion mobility-mass spectrometry. J. Proteome Res. 2002, 1, 303-306.

15. Wyttenbach, T.; von Helden, G.; Bowers, M. T. Gas-phase conformation of biological molecules: Bradykinin. J. Am. Chem. Soc. 1996, 118, 8355-8364.

16. Ruotolo, B. T.; Tate, C. C.; Russell, D. H. Ion mobility-mass spectrometry applied to cyclic peptide analysis: Conformational preferences of gramicidin $\mathrm{S}$ and linear analogs in the gas phase. J. Am. Soc. Mass Spectrom. 2004, 15, 870-878.

17. Asbury, G. R.; Hill, H. H. Using different drift gases to change separation factors $(\alpha)$ in ion mobility spectrometry. Anal. Chem. 2000, 72, 580-584.

18. Purves, R. W.; Guevremont, R.; Day, S.; Pipich, C. W.; Matyjaszczyk, M. S. Mass spectrometric characterization of a highfield asymmetric waveform ion mobility spectrometer. Rev. Sci. Instrum. 1998, 69, 4094-4105.

19. Beegle, L. W.; Kanik, I.; Matz, L.; Hill, H. H. Effects of drift-gas polarizability on glycine peptides in ion mobility spectrometry. Int. J. Mass Spectrom. 2002, 216, 257-268.
20. Matz, L. M.; Hill, H. H.; Beegle, L. W.; Kanik, I. Investigation of drift gas selectivity in high resolution ion mobility spectrometry with mass spectrometry detection. J. Am. Soc. Mass Spectrom. 2002, 13, 300-307.

21. McDaniel, E. W.; Mason, E. A. The Mobility and Diffusion of Ions in Gases; Wiley: New York, 1973, p. 372

22. For examples of recent applications of FAIMS technology see: (a) Cui, M.; Ding, L.; Mester, Z. Separation of cisplatin and its hydrolysis products using electrospray ionization high-field asymmetric waveform ion mobility spectrometry coupled with ion trap mass spectrometry. Anal. Chem. 2003, 75, 58475853. (b) Gabryelski, W.; Froese, K. L. Characterization of naphthenic acids by electrospray ionization high-field asymmetric waveform ion mobility spectrometry mass spectrometry. Anal. Chem. 2003, 75, 4612-4623. (c) Gabryelski, W.; Froese, K. L. Rapid and sensitive differentiation of anomers, linkage, and position isomers of disaccharides using high-field asymmetric waveform ion mobility spectrometry (FAIMS). J. Am. Soc. Mass Spectrom. 2003, 14, 265-277.

23. Barnett, D. A.; Ells, B.; Guevremont, R.; Purves, R. W. Application of ESI-FAIMS-MS to the analysis of tryptic peptides. J. Am. Soc. Mass Spectrom. 2002, 13, 1282-1291.

24. Ewing, R. G.; Eiceman, G. A.; Stone, J. A. Proton bound cluster ions in ion mobility spectrometry. Int. J. Mass Spectrom. 1999, 193, 57-68.

25. Krylova, N.; Krylov, E.; Eiceman, G. A.; Stone, J. A. Effect of moisture on the field dependence of mobility for gas-phase ions of organophosphorus compounds at atmospheric pressure with field asymmetric ion mobility spectrometry. J. Phys. Chem. A 2003, 107, 3648-3654.

26. McLean, J. A.; Russell, D. H. Sub-femtomole peptide detection in ion mobility time-of- flight mass spectrometry measurements. J. Proteome Res. 2003, 2, 428.

27. Asbury, G. R.; Hill, H. H. Evaluation of ultrahigh resolution ion mobility spectrometry as an analytical separation device in chromatographic terms. J. Microcolumn Sep. 2000, 12, 172.

28. Park, Z. Y., Russell, D. H. Thermal Denaturation: A useful technique in peptide mass mapping. Anal. Chem. 2000, 72, 2667.

29. Gillig, K. J.; Ruotolo, B. T.; Stone, E. G.; Russell, D. H. Periodic focusing ion mobility spectrometer/mass spectrometer, unpublished.

30. Gillig, K. J.; Russell, D. H. U.S. Patent 6,639,213, Oct. 28, 2003.

31. Mason, E. A. In Plasma Chromatography; T. W. Carr, Ed., Plenum Press; New York, NY, 1984, p 50. Equation 12.

32. Valentine, S. J.; Counterman, A. E.; Clemmer, D. E. A database of 660 peptide ion cross sections: Use of intrinsic size parameters for bona fide predictions of cross sections J. Am. Soc. Mass Spectrom. 1999, 10, 1188.

33. Fuhrer, K.; Gonin, M.; McCully, M. I.; Egan, T.; Ulrich, S. R.; Vaughn, V. W.; Burton W. D.; Schultz, J. A.; Gillig, K.; Russell, D. H. Monitoring Fast Processes with TOFMS Proceedings of the 49th Annual Conference on Mass Spectrometry and Allied Topics; Chicago, IL, May 2001.

34. Wannier, G. H. Bell System Tech. J. 1953, 32, 170.

35. Loeb, L. B. Basic Processes of Gaseous Electronics, 2nd ed.; University of California Press: Berkeley, CA, 1961, p 1028.

36. Von Engle, A. Ionized Gases, 2nd ed.; Clarendon Press: Oxford, 1965, p 325.

37. Viehland, L. A.; Mason, E. A. At. Data Nucl. Data Tables. 1995, 60, 37-95.

38. Nanbu, K.; Wakayama, G. Phys. Rev. E 2001, 63, 062201.

39. Guevremont, R.; Barnett, D. A.; Purves, R. W.; Vandermey, J. Analysis of a tryptic digest of pig hemoglobin using ESIFAIMS-MS. Anal. Chem. 2000, 72, 4577. 